Article

\title{
Polyvinylpyridine-Supported Palladium Nanoparticles: An Efficient Catalyst for Suzuki-Miyaura Coupling Reactions
}

\author{
Graziano Fusini ${ }^{1,+}{ }^{,}$Fabio Rizzo $^{2}{ }^{(D)}$, Gaetano Angelici ${ }^{1}\left(\mathbb{0}\right.$, Emanuela Pitzalis $^{3}$, \\ Claudio Evangelisti ${ }^{3, *(D)}$ and Adriano Carpita ${ }^{1, \ddagger}$ \\ 1 Dept Chem \& Ind Chem, University of Pisa, Via G Moruzzi 13, I-56124 Pisa, Italy; \\ graziano.fusini@dipharma.com (G.F.); gaetano.angelici@unipi.it (G.A.); adriano.carpita@unipi.it (A.C.) \\ 2 CNR, Istituto di Scienze e Tecnologie Chimiche "Giulio Natta" (SCITEC), via C. Golgi 19, I-20133 Milano, \\ Italy; fabio.rizzo@cnr.it \\ 3 CNR, Istituto di Chimica dei Composti Organometallici (ICCOM), Via G. Moruzzi 1, I-56124 Pisa, Italy; \\ emanuela.pitzalis@pi.iccom.cnr.it \\ * Correspondence: claudio.evangelisti@cnr.it \\ † Current address: Dipharma Francis S.r.l., Via Bissone 5, I-20021 Baranzate (MI), Italy. \\ $\ddagger$ Deceased before the submission.
}

Received: 26 February 2020; Accepted: 13 March 2020; Published: 15 March 2020

\begin{abstract}
Palladium nanoparticles (Pd NPs) synthesized by the metal vapor synthesis technique were supported on poly(4-vinylpyridine) $2 \%$ cross-linked with divinylbenzene (Pd/PVPy). Transmission electron microscopy revealed the presence of small metal nanoparticles $\left(\mathrm{d}_{\mathrm{m}}=2.9 \mathrm{~nm}\right)$ highly dispersed on the PVPy. The Pd/PVPy system showed high catalytic efficiency in Suzuki-Miyaura carbon-carbon coupling reactions of both non-activated and deactivated aromatic iodides and bromides with aryl boronic acids, carried out under an air atmosphere. The high turnover of the catalyst and the ability of the PVPy resin to retain active Pd species are highlighted. By comparing the catalytic performances of Pd/PVPy with those observed by using commercially available Pd-based supported catalysts, the reported system showed higher selectivity and lower Pd leaching.
\end{abstract}

Keywords: Pd catalysts; metal vapor synthesis; polyvinylpyridine; Suzuki-Miyaura reaction

\section{Introduction}

The palladium-catalyzed coupling of organoboron reagents with aryl halides, known as the Suzuki-Miyaura reaction [1-3] is one of the most convenient and powerful synthetic methods for the preparation of biaryl and alkene derivatives that are essential components of natural products, pharmaceuticals, agrochemicals, and polymers [4-6]. The reaction is mainly unaffected by water, tolerating a huge range of functionality and leading to non-toxic by-products [7]. Traditional reaction conditions for Suzuki-Miyaura couplings involve the use of homogeneous palladium catalysts containing phosphine ligands [1,8-11] or N-heterocyclic carbene ligands [12-14].

This reaction is the most intensively investigated among C-C couplings in the last decade [15-17]. Buchwald and coworkers [18,19] and Fu and coworkers [20] reported the possibility of exploiting this reaction with different compounds such as less-active aryl chlorides, hindered substrates, hetero-aromatic compounds, and alkenyl derivatives as well as at room temperature and in the presence of low-catalyst-loading. However, the main disadvantages are the availability, stability, and cost of the palladium organometallic complexes as well as of the ligands. Furthermore, homogeneous palladium catalysts are typically not reusable and the products are often contaminated by residual palladium and/or ligands, which in turn are difficult to separate from the products [3,21]. These limitations of 
homogeneous catalysis boosted the development of new strategies for transition-metal catalysis, which allows for catalyst recovery and reuse. In this framework, supported palladium catalysts can offer several advantages, as they can be easily purified by simple filtration from the reaction mixture and recycled for further reactions, if the active sites have not become deactivated. Moreover, this latter approach can reduce waste derived from reaction workup, favoring the development of green chemical processes [22,23].

For this purpose, palladium salts, organometallic complexes, or Pd nanoparticles (NPs) [24] have been immobilized on a wide range of organic or inorganic supports (e.g., polystyrene [25-27], polyurea [28], polydopamine [29] carbon [30,31], montmorillonite [32], gold [33], zeolites [34], silica gels [35-40]) by covalent, ionic bonding, adsorption, or encapsulation to obtain recoverable supported palladium catalysts [41]. Using a different approach, Schüth and coworkers recently reported the synthesis of Pd NPs confined into a porous polyphenylene network obtained by direct palladium-catalyzed Suzuki-Miyaura coupling. The solid composite was shown to be a very active catalyst for Suzuki coupling reactions [42]. Despite the advantages described above, supported catalysts often suffer from reduced mass transfer and lower catalytic efficiency than homogeneous ones. Moreover, they rapidly lose catalytic activity when reused, mainly due to a re-structuring of the active site leading to Pd NP aggregation as well as Pd leaching [43]. In 2006, McQuade and coworkers reported that the polyurea-encapsulated PdEnCat, a commercially available catalyst used in Mizoroki-Heck and Suzuki-Miyaura coupling reaction, actually acted as a Pd reservoir of soluble catalytic species [44]. As a matter of fact, the TEM analysis of the supernatant from the Heck reaction catalyzed by Pd EnCat ${ }^{\circledR} 30$ clearly revealed metal leaching, leading to the formation of Pd nanoparticles ranging from 5 to $10 \mathrm{~nm}$ in size. In the same year, Park and co-workers reported that polystyrene (cross-linked with divinylbenzene) beads doped with palladium quickly loses the original activity in the same reaction, with a yield that in the third cycle was lowered to only $38 \%$ from the original $98 \%$ [45]. This behavior was addicted to Pd leaching and Pd nanoparticle aggregation occurring during the Suzuki-Miyaura coupling reaction.

Some years ago, we described the preparation of Pd NPs by metal vapor synthesis (MVS) supported on a commercially available poly(4-vinylpyridine) cross-linked with divinylbenzene resin (PVPy), acting as an effective catalyst for Heck-type alkenylations [46]. The catalyst was particularly active and stable, ensuring a very low Pd leaching, and was effectively re-used for further reaction cycles. Herein, we report on the use of a PVPy-supported Pd catalyst for the synthesis of biaryls via the Suzuki-Miyaura couplings of aryl halides with arylboronic acids under air atmosphere.

\section{Results and Discussion}

\subsection{Characterization of Polyvinylpyridine-Supported Palladium (Pd/PVPy) Catalyst}

Polyvinylpyridine-supported palladium catalyst, Pd/PVPy, was synthesized according to the previously reported MVS approach [46]. TEM micrographs of the Pd/PVPy (Figure 1) show the PVPy polymer homogeneously populated by Pd nanoparticles in the range $0.5-8.0 \mathrm{~nm}$, with a mean diameter close to $2.9 \mathrm{~nm}$. High resolution TEM analysis (Figure S1) indicates the presence of metal particles well included into the polymeric resin, in agreement with the previously reported data emphasizing the strong affinity of MVS-derived Pd NPs with the pyridine moiety of the support [46-50]. Moreover, lattice fringe analysis, recorded on Pd nanoparticles, showed spots in the FFT pattern at $2.26 \AA$ that can be ascribed to the spacing of (llll) planes of the face centered cubic (fcc) structure of metallic Pd. 

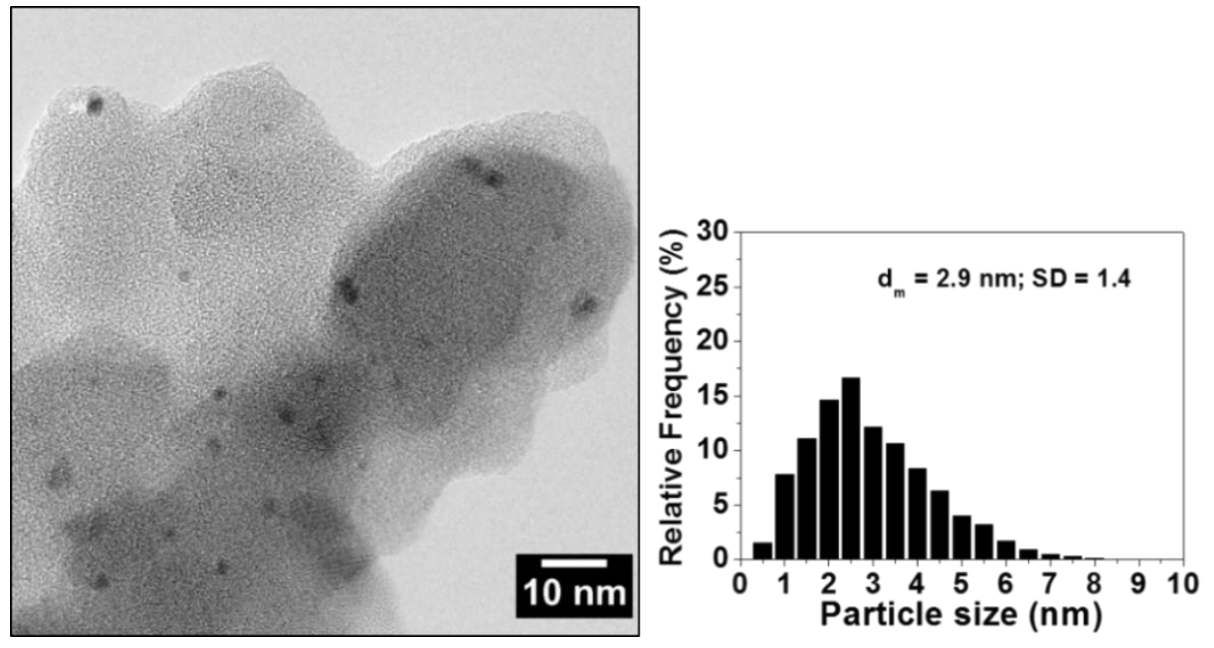

Figure 1. Representative transmission electron microscopy micrograph and histogram of particle size distribution of the polyvinylpyridine-supported palladium catalyst (Pd/PVPy).

\subsection{Catalytic Activity in Suzuki-Miyaura Reaction}

The reaction between 4-bromotoluene (1a) and phenylboronic acid (2a) was chosen as a model reaction to evaluate the catalytic behavior of the Pd/PVPy system. In order to optimize the experimental conditions, the factors affecting the conversion and the selectivity of the reaction (i.e., solvent and base) were initially evaluated in the presence of $0.50 \mathrm{~mol} \%$ of Pd/PVPy, under an argon atmosphere (Table S1). The best results were obtained using DMA/ $\mathrm{H}_{2} \mathrm{O}(4: 1)$ as the solvent and $\mathrm{K}_{3} \mathrm{PO}_{4}$ as the base (3 equivalent) at $120{ }^{\circ} \mathrm{C}$. In these conditions after $7 \mathrm{~h}$ of reaction, the conversion into the 4-methylbiphenyl (3a) cross-coupling product with a yield of $64 \%$ occurred along with a complete selectivity. Surprisingly, inorganic bases commonly used for Suzuki-Miyaura reaction (i.e., $\mathrm{Na}_{2} \mathrm{CO}_{3}, \mathrm{NaHCO}_{3}$, and $\mathrm{NaOH}$ ) led to poor results. On the other hand, using strong bases such as KF promoted an extensive dehalogenation of the aryl halide as well as the formation of homo-coupling side product. Regarding the solvent employed in the reaction, the mixture DMA/ $\mathrm{H}_{2} \mathrm{O}(4: 1)$ led to the best results without the presence of side reaction products. As a matter of fact, the use of water alone or in combination with alcohols such as $i-\mathrm{PrOH} / \mathrm{H}_{2} \mathrm{O}(1: 1)$ and $\mathrm{EtOH} / \mathrm{H}_{2} \mathrm{O}$ (1:1), and aprotic polar/aqueous solvents (i.e., $\mathrm{NMP} / \mathrm{H}_{2} \mathrm{O}$ (4:1) and 1,2-dioxane $\left./ \mathrm{H}_{2} \mathrm{O}(4: 1)\right)$ resulted in lower yields of the cross-coupling product. Further investigations revealed that the amount of Pd/PVPy can be effectively decreased from 0.5 to $0.15 \mathrm{Pd} \mathrm{mol} \mathrm{\%} \mathrm{without}$ significant loss of yield of the 3a product (Table 1, entries 1-3). Nevertheless, a further decrease of the catalyst amount to $0.10 \mathrm{Pd} \mathrm{mol} \mathrm{\%} \mathrm{led} \mathrm{to} \mathrm{a} \mathrm{drop} \mathrm{in} \mathrm{the} \mathrm{yield} \mathrm{of} \mathrm{3a} \mathrm{(entry} \mathrm{4).} \mathrm{Finally,} \mathrm{the} \mathrm{possibility} \mathrm{of}$ carrying out the Suzuki-Miyaura coupling under aerobic conditions was investigated. Under these latter conditions, the activity of the Pd/PVPy catalyst was remarkably enhanced, while the selectivity appeared comparable with that obtained under an inert atmosphere (entry 5). As expected, the reaction needed less mild conditions (e.g., higher temperature and longer reaction time) than those reported with Pd organometallic complexes for reactions carried out in the homogeneous phase (see e.g., [13]). However, as discussed above, the use of supported catalysts is a valid alternative in order to (i) facilitate the reaction workup, (ii) limit the Pd contamination of the reaction product, and (iii) favor the reusability of the catalyst.

These results agree with evidence previously reported by other authors on the beneficial effect of the oxygen [43,49-52]. The observed increase in catalytic activity has been ascribed to the formation of oxidized Pd species onto the surface of Pd NPs. As a consequence, the oxidized Pd atoms can be easily released into the solution, leading to "peroxo-palladium complexes" that are stable against aggregation. Moreover, they can directly undergo transmetalation with the arylboronic due to the enhancement of the electron density of palladium. 
Table 1. Suzuki-Miyaura reaction catalyzed by the Pd/PVPy catalyst ${ }^{\mathrm{a}}$.

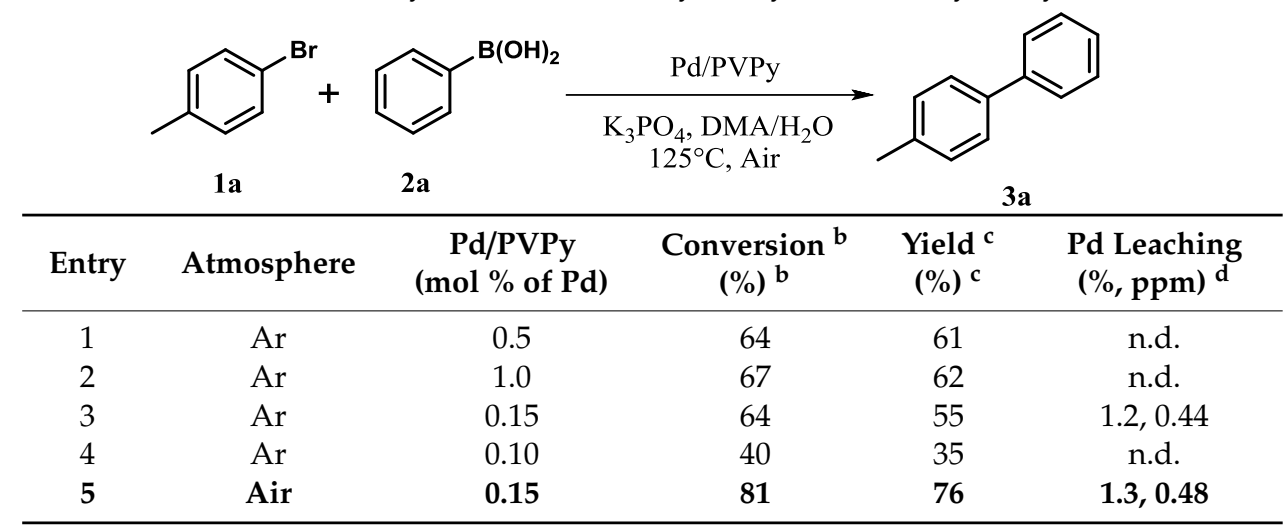

${ }^{a}$ Reaction conditions: $1.00 \mathrm{mmol}$ of $\mathbf{1 a}, 1,25 \mathrm{mmol}$ of $\mathbf{2 a}, \mathrm{K}_{3} \mathrm{PO}_{4}(3 \mathrm{mmol}), \mathrm{Pd} / \mathrm{PVPy}, \mathrm{DMA} / \mathrm{H}_{2} \mathrm{O}(4: 1)(4 \mathrm{~mL})$, $\mathrm{T}=125^{\circ} \mathrm{C}, \mathrm{t}=7 \mathrm{~h} .{ }^{\mathrm{b}}$ Evaluated by GC, and determined by the area ratio between product $3 \mathrm{a}$ and total area of $\mathbf{1 a}$ and 3a. ${ }^{c}$ Yield of $3 a$ evaluated by GLC, determined by internal standard (naphthalene). ${ }^{\mathrm{d}}$ Evaluated by ICP-OES after microfiltration $(0.22 \mu \mathrm{m})$.

Additionally, we investigated the Pd leached into the reaction mixture by inductively coupled plasma-optical emission spectroscopy analysis in order to evaluate the amount of Pd released in solution from the Pd/PVPy catalysts under the above mentioned reaction conditions. Furthermore, with the same analysis, we can also obtain information on the capability of the polymeric support to quench the Pd species in solution. For this purpose, after $7 \mathrm{~h}$, the reaction mixture was filtered through a polytetrafluoroethylene syringe filter $(0.22 \mu \mathrm{m}$ diameter) and a portion of the filtrate was dissolved by nitric acid after solvent evaporation. The levels of Pd contamination detected on reactions carried out both in argon and in air atmosphere were exceptionally very low. The obtained values of $0.44 \mathrm{ppm}$ and $0.48 \mathrm{ppm}$ for reaction in argon and air, respectively, corresponded to a Pd leached of 1.2 and 1.3 $\mathrm{wt} \%$ of the initial available Pd amount in the catalyst. Moreover, the filtrate solution was newly heated at $125^{\circ} \mathrm{C}$ and the reaction conversion was monitored to check that the catalytic species was still present in the mixture (Figure 2). The results show that the reaction without the solid catalyst afforded only $1 \%$ of conversion after $17 \mathrm{~h}$, indicating that the catalytically active $\mathrm{Pd}$ species were effectively removed.

It is worth noting that the leaching test and filtration test alone cannot univocally establish the real nature of the active catalyst (i.e., heterogeneous or homogeneous), as the support can catch the leached Pd so fast that it may not be revealed by the leaching or hot filtration test $[43,53]$. However, the ability of the PVPy resin to coordinate palladium active species formed in carbon-carbon coupling reactions was previously described [54,55].

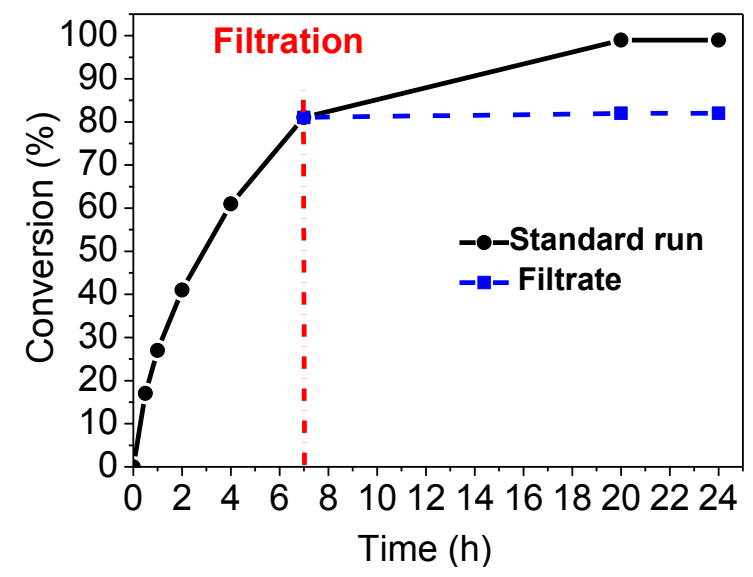

Figure 2. Conversion and hot filtration test during the Suzuki-Miyaura coupling reaction of 4-bromotoluene (1a) with phenylboronic acid (2a) over Pd/PVPy (see footnotes to Table 1 for experimental conditions). 
From the data described above, the Pd/PVPy system has the requisites to be transferred into industrial applications. Indeed, from an applicative point of view, the Pd/PVPy catalyst can effectively reduce the issue of the metal contamination in products prepared via the Suzuki-Miyaura cross-coupling reaction (e.g., for the synthesis of active pharmaceutical intermediates), avoiding the time-consuming and expensive cleaning steps needed in order to remove the $\mathrm{Pd}$ residue.

In order to further investigate the applicability of the Pd/PVPy catalyst, we extended the substrate scope by creating a library of suitable aryl halide and boronic acid investigated under the optimized reaction conditions (Table 2). Deactivated aryl iodides as well as activated and deactivated aryl bromides were completely converted with a yield of the corresponding isolated products ranging from 58 to $99 \%$. The reaction exhibited good diversity with both electron withdrawing and donating groups. For the deactivated aryl halides sterically hindered, both bromides and iodides, a satisfactory yield could be obtained increasing the reaction time (entries 11-14). Interestingly, both protic free groups (i.e., $\mathrm{NH}_{2}$ and $\mathrm{OH}$ ) were well-tolerated in the reaction (entries 16-18). Furthermore, aryl chlorides (entry 19) were converted with low yield into the product even after a longer reaction time because of their low reactivity, as a consequence of their reluctance to oxidatively add to $\operatorname{Pd}(0)$. Regarding aryl boronic acids, the coupling reaction of electron-rich aryl boronic acid (e.g., 4-methoxyphenylboronic acid, (2b)) proceeded more efficiently when compared with non-substituted phenylboronic acid (2a). Noteworthy, the reaction with aryl boronic acid sterically hindered such as 2-methoxyphenylboronic acid (2c) led to the corresponding product in moderate yield (48\%) in conjunction with the product of homocoupling (entry 15).

Table 2. Suzuki-Miyaura coupling reactions catalyzed by $\mathrm{Pd} / \mathrm{PVPy}{ }^{\mathrm{a}}$.

Entry


Table 2. Cont.

\begin{tabular}{|c|c|c|c|c|c|}
\hline Entry & $\begin{array}{c}\text { (Het)Ar-X } \\
1\end{array}$ & $\begin{array}{c}\mathrm{Ar} \mathbf{r}^{\prime}-\mathrm{B}(\mathrm{OH})_{2} \\
2\end{array}$ & $\begin{array}{l}\text { Time } \\
\text { (h) }\end{array}$ & $\begin{array}{c}\text { Product } \\
3\end{array}$ & $\begin{array}{c}\text { Yield }^{b} \\
(\%)\end{array}$ \\
\hline 9 & $1 \mathrm{a}$ & & 12 & & 92 \\
\hline 10 & & & 1.0 & & 94 \\
\hline 11 & & & 24 & & 72 \\
\hline 12 & & & 3.5 & & 84 \\
\hline 13 & & & 24 & & 67 \\
\hline 14 & & & 18 & & 80 \\
\hline 15 & & & 24 & & 48 \\
\hline 16 & & & 24 & & 58 \\
\hline 17 & & & 20 & & 86 \\
\hline 18 & 1 & $2 d$ & 24 & $3 q$ & 64 \\
\hline 19 & & & 48 & & 16 \\
\hline
\end{tabular}

a Reaction conditions: $2.00 \mathrm{mmol}$ of 1, $2.50 \mathrm{mmol}$ of 2, $\mathrm{K}_{3} \mathrm{PO}_{4}(6 \mathrm{mmol}), \mathrm{Pd} / \mathrm{PVPy}(0.15 \mathrm{~mol} \%$ of $\mathrm{Pd}), 4.0 \mathrm{~mL}$ DMA $/ \mathrm{H}_{2} \mathrm{O}(4: 1), \mathrm{T}=125^{\circ} \mathrm{C}$. ${ }^{\mathrm{b}}$ Isolated yield evaluated by medium pressure liquid chromatography purification on silica gel.

\subsection{Catalyst Reusability}

We investigated the lifetime of the Pd/PVPy catalyst and its level of reusability in consecutive Suzuki-Miyaura reactions using both an electron-poor aryl bromide (e.g., 4-bromonitrobenzene, 1a) and an electron-rich aryl bromide (e.g., 4-bromotoluene, 1b) in combination with the phenylboronic acid (2a) (Figure 3). After each cycle, the catalyst was recovered by filtration and afterward washed with water and acetone and then dried under vacuum. The solid catalyst was then reused without further activation. As a result, the catalyst showed a comparable performance for five consecutive 
runs, showing a slight decrease of the efficiency only during the fifth catalytic cycle. TEM analysis of a $\mathrm{Pd} / \mathrm{PVPy}$ sample recovered after the first catalytic run (Figure 4, right side) confirmed only a slight increase in the particle size $\left(\mathrm{d}_{\mathrm{m}}=3.5 \mathrm{~nm}\right)$ with respect to the freshly prepared sample.

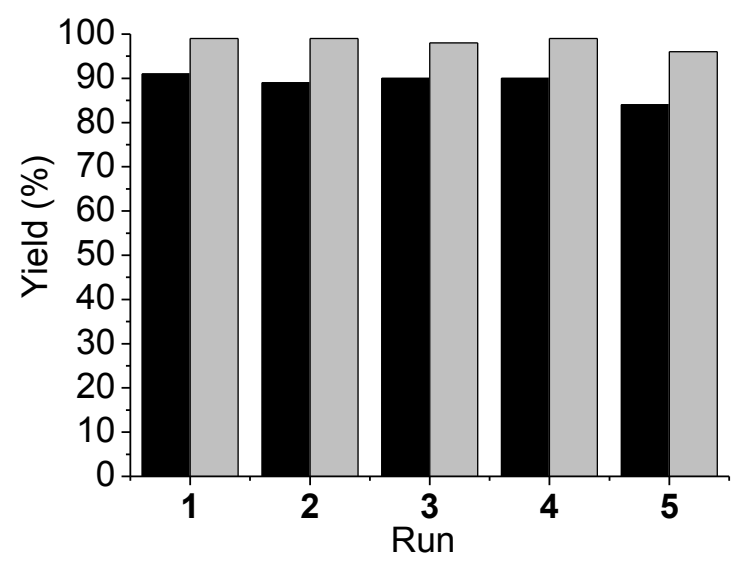

Figure 3. Recycling tests on Pd/PVPy catalysts for the Suzuki-Miyaura coupling reaction of 4-bromotoluene (1a, black bars) and 4-bromonitrobenzene (1 $\mathbf{b}$, grey bars) with phenylboronic acid (2a) (see Table 2 for experimental conditions).
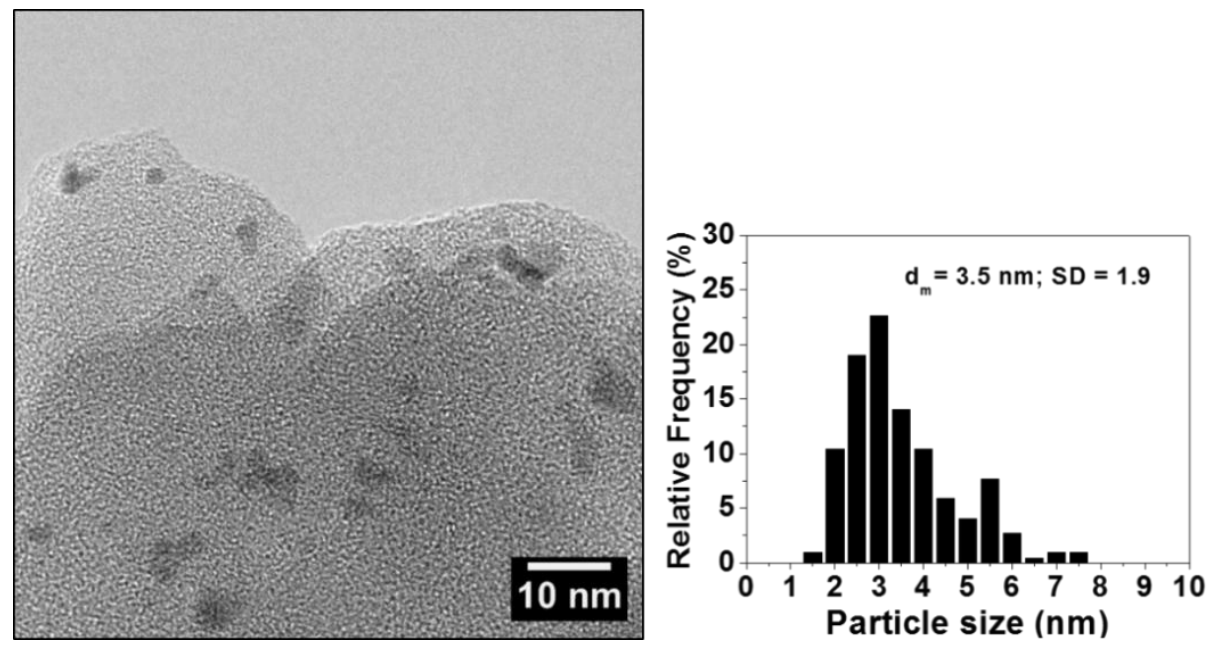

Figure 4. Representative transmission electron microscopymicrograph and histogram of particle size distribution of Pd/PVPy system after the first catalytic cycle.

\subsection{Comparison with Commercially Available Pd-Based Catalysts}

The catalytic performances of the Pd/PVPy system used in the reaction of 4-bromonitrobenzene (1a) with phenylboronic acid (2a) was compared with other commercially available heterogeneous catalysts such as $\mathrm{Pd} / \mathrm{C}$ and palladium acetate microencapsulated in polyurea matrix (Pd EnCat ${ }^{\circledR} 40$ ) (Table 3). The results showed that Pd/PVPy led to the best results in terms of selectivity $(99.9 \%)$, without the formation of the homocoupling side-product. Moreover, the presented system provides a lower Pd leaching (1.3 Pd wt \% of the initial Pd content) than the other commercially available systems examined (2.2-2.6 Pd wt \% of the initial Pd content). 
Table 3. Comparison of the performances of Pd/PVPy in the Suzuki-Miyaura reaction ${ }^{\mathrm{a}}$.

\begin{tabular}{cccccc}
\hline Entry & Catalyst & $\begin{array}{c}\text { Conversion } \\
\mathbf{( \% )}\end{array}$ & $\begin{array}{c}\text { Selectivity }^{\mathbf{b}} \\
\mathbf{3 a / 3 b}\end{array}$ & $\begin{array}{c}\text { Yield }^{\mathbf{c}} \\
\mathbf{( \% )}\end{array}$ & $\begin{array}{c}\text { Pd Leaching }^{\mathbf{d}} \\
\mathbf{( \% ,} \mathbf{p p m})\end{array}$ \\
\hline 1 & $\mathrm{Pd} / \mathrm{PVPy}$ & 81 & $99.9 / 0.1$ & 76 & $1.3,0.48$ \\
2 & $\mathrm{Pd} / \mathrm{C}$ & 99 & $90 / 10$ & 75 & $7.2,2.67$ \\
3 & $\mathrm{Pd} \mathrm{EnCat}^{\circledR} 40$ & 97 & $98 / 2$ & 62 & $2.4,0.89$ \\
\hline
\end{tabular}

a Reaction conditions: $2.00 \mathrm{mmol}$ of $\mathbf{1 a}, 2.50 \mathrm{mmol}$ of $\mathbf{2 a}, 6.00 \mathrm{mmol}$ of $\mathrm{K}_{3} \mathrm{PO}_{4}, 0.15 \mathrm{~mol} \%$ of Pd $(0.0030 \mathrm{mmol} \mathrm{Pd})$, $4 \mathrm{~mL}$ DMA/ $\mathrm{H}_{2} \mathrm{O}(4: 1), \mathrm{T}=125{ }^{\circ} \mathrm{C}, \mathrm{t}=7 \mathrm{~h} .{ }^{\mathrm{b}}$ Evaluated by GC; ${ }^{\mathrm{c}}$ Yield of 3a evaluated by GLC, determined by internal standard (naphthalene). ${ }^{d}$ Evaluated by inductively coupled plasma-optical emission spectroscopy after microfiltration $(0.22 \mu \mathrm{m})$.

\section{Materials and Methods}

All operations involving the MVS products were carried out under an argon atmosphere. The co-condensation of palladium and the solvent was carried out in a previously described static reactor [46]. Solvents were purified by conventional methods, distilled, and stored under argon. Poly(4-vinylpyridine) $2 \%$ cross-linked with divinylbenzene (PVPy), Pd/C, and Pd EnCat ${ }^{\circledR} 40$ were from Merck (Darmstadt, Germany). $\mathrm{K}_{3} \mathrm{PO}_{4}$, aryl iodides, aryl bromides, and boronic acids were from Merck and used as received.

Gas-liquid chromatography (GLC) analyses were performed on a Dani GC1000 gas chromatograph (Milano, Italy), equipped with a flame ionization detector (FID) using a $\mathrm{SiO}_{2}$ capillary column FSOT Alltech (AT-5, $30 \mathrm{~m} \times 0,25 \mathrm{~mm}$ i.d.) and nitrogen as the carrier gas. Gas-liquid chromatography-mass spectrometry (GLC-MS) analyses were performed on an Agilent 6890 Network GC System (Santa Clara, CA, USA), equipped with an electron impact mass detector (Agilent 5973 Network Mass Selective Detector) using a $\mathrm{SiO}_{2}$ capillary column FSOT Agilent (HP-5MS, $30 \mathrm{~m} \times 0,25 \mathrm{~mm}$ i.d.) with helium as the carrier gas. Inductively coupled plasma-optical emission (ICP-OES) analysis was carried out by inductively coupled plasma-optical emission spectroscopy (ICP-OES) (Perkin Elmer Optima 8000, Waltham, MA, USA) and an external calibration methodology. The limit of detection (LOD) calculated for palladium was $2 \mathrm{ppb}$.

Transmission electron microscopy (TEM) analysis was performed by a ZEISS LIBRA200FE microscope (Oberkochen, Germany) equipped with a $200 \mathrm{kV}$ field-emission gun source. The sample was finely smashed in an agate mortar, suspended in toluene and sonicated, then the suspension was dropped onto a holey carbon coated copper grid (300 mesh) followed by the evaporation of the solvent.

\subsection{Preparation of Pd/PVPy System}

In a typical experiment, $\mathrm{Pd}$ vapor, generated at $10^{-4} \mathrm{mbar}$ by resistive heating of the metal $(500 \mathrm{mg})$ in an alumina-coated tungsten crucible, was co-condensed at liquid nitrogen temperature with a 1:1 mixture of mesitylene $(30 \mathrm{~mL})$ and 1-hexene $(30 \mathrm{~mL})$. The reactor chamber was then heated to the melting point of the solid matrix, and the resulting red-brown solution was siphoned and handled at low temperature $\left(-30 /-40^{\circ} \mathrm{C}\right)$.

For ICP-OES analysis, the metal-containing mesitylene/1-hexene solution $(1 \mathrm{~mL})$ was heated in a porcelain crucible over a heating plate and the solvent was evaporated. The solid residue was dissolved in aqua regia $(2 \mathrm{~mL})$, heated until complete evaporation and the solid residue was dissolved in $0.5 \mathrm{M}$ aqueous $\mathrm{HCl}$. The palladium content of the solvated metal solution was $2.8 \mathrm{mg} / \mathrm{mL}$. The mesitylene/1-hexene Pd atoms solution ( $36 \mathrm{~mL}, 100.8 \mathrm{mg} \mathrm{Pd}$ ) was added to a suspension of PVPy (10 g) in mesitylene $(30 \mathrm{~mL})$. The mixture was stirred at room temperature for $24 \mathrm{~h}$. The colorless solution was removed and the light-brown solid was washed with $n$-pentane $(3 \times 40 \mathrm{~mL})$ and dried under reduced pressure. The metal content of Pd on the PVPy catalyst (1.0 wt \% Pd) was determined by ICP-OES analysis. 


\subsection{General Procedure for the Suzuki-Miyaura Reactions}

\subsubsection{Suzuki-Miyaura Reactions}

Aryl halides $(2.0 \mathrm{mmol})$, aryl boronic acid $(2.5 \mathrm{mmol}), \mathrm{K}_{3} \mathrm{PO}_{4} \cdot 12 \mathrm{H}_{2} \mathrm{O}(6.0 \mathrm{mmol}), \mathrm{Pd} / \mathrm{PVPy}(32 \mathrm{mg}$, $\left.3.0 \times 10^{-3} \mathrm{mmol} \mathrm{Pd}\right)$, and DMA: $\mathrm{H}_{2} \mathrm{O} 4: 1(4 \mathrm{~mL})$ were introduced into a $25 \mathrm{~mL}$ round-bottomed, two-necked flask equipped with a stirring magnetic bar, a condenser, and a silicon stopper. The reaction mixture was stirred at $125^{\circ} \mathrm{C}$. For GLC analysis, the samples were treated with $0.5 \mathrm{M}$ aqueous $\mathrm{HCl}$. The organic products were then extracted with diethyl ether, and dried over anhydrous sodium sulfate. The coupling products were purified by column medium-pressure chromatography (silica, solvent mixture). The reaction was stopped at the time reported in Table 2. All the products were characterized by using mass spectrometry (see Supplementary Materials).

\subsubsection{Recycling Tests}

The coupling reaction of aryl bromide (1a and $\mathbf{1 b}$ ) with phenylboronic acid (2a) was carried out as described in the general procedure of Suzuki-Miyaura cross-coupling reactions (4.2.1.). After filtering off the product, the catalyst was washed with $\mathrm{H}_{2} \mathrm{O}(3 \times 10 \mathrm{~mL})$, acetone $(3 \times 5 \mathrm{~mL})$, and $\mathrm{Et}_{2} \mathrm{O}(3 \times 5 \mathrm{~mL})$, respectively, and dried under vacuum for $12 \mathrm{~h}$. Then, the recovered catalyst was used in a further coupling experiment.

\section{Conclusions}

In conclusion, the Pd/PVPy catalytic system synthesized by the MVS approach is an effective catalyst for the Suzuki-Miyaura coupling reaction under aerobic conditions. This catalyst remarkably expands the scope of palladium supported catalysts by enabling the possibility of using various arylboronic acids for the coupling of aryl bromides. The catalytic system exhibits high recyclability, with coupling yields preserved over five catalytic cycles, and a very low Pd leaching (i.e., product contamination). Further applications of the reported system can be foreseen due to the high versatility of this catalyst.

Supplementary Materials: The following are available online at http://www.mdpi.com/2073-4344/10/3/330/s1, Figure S1: High resolution TEM micrograph (800000X) of Pd/PVPy and FFT pattern taken from the yellow squared area, Table S1: Optimization reaction conditions: Isolation and characterization of Suzuki-Miyaura products.

Author Contributions: Conceptualization, C.E. and A.C.; supervision, C.E. and A.C.; experimental investigation, G.F., F.R., E.P., and C.E.; writing-original draft preparation, C.E.; writing-review and editing, G.A., F.R., and E.P.; funding acquisition, C.E. and A.C. All authors have read and agreed to the published version of the manuscript.

Funding: This research was funded by the Italian Ministry of University and Scientific Research (MIUR), grant number "RBFR10BF5V".

Conflicts of Interest: The authors declare no conflict of interest.

\section{References}

1. Suzuki, A. Cross-Coupling Reactions Of Organoboranes: An Easy Way To Construct C-C Bonds (Nobel Lecture). Angew. Chem. Int. Ed. 2011, 50, 6722-6737. [CrossRef] [PubMed]

2. Miyaura, N.; Suzuki, A. Palladium-Catalyzed Cross-Coupling Reactions of Organoboron Compounds. Chem. Rev. 1995, 95, 2457-2483. [CrossRef]

3. Miyaura, N. Metal-Catalyzed Cross-Coupling Reactions of Organoboron Compounds with Organic Halides. In Metal-Catalyzed Cross-Coupling Reactions, 2nd ed.; Diederich, F., Stang, P.J., Eds.; Wiley-VCH: New York, NY, USA, 2004; pp. 41-123.

4. Magano, J.; Dunetz, J.R. Large-Scale Applications of Transition Metal-Catalyzed Couplings for the Synthesis of Pharmaceuticals. Chem. Rev. 2011, 111, 2177-2250. [CrossRef] [PubMed]

5. Torborg, C.; Beller, M. Recent Applications of Palladium-Catalyzed Coupling Reactions in the Pharmaceutical, Agrochemical, and Fine Chemical Industries. Adv. Synth. Catal. 2009, 351, 3027-3043. [CrossRef] 
6. Nicolaou, K.C.; Bulger, P.G.; Sarlah, D. Palladium-catalyzed cross-coupling reactions in total synthesis. Angew. Chem. Int. Ed. 2005, 44, 4442-4489. [CrossRef]

7. Hooshmand, S.E.; Heidari, B.; Sedghi, R.; Varma, R.S. Recent advances in the Suzuki-Miyaura cross-coupling reaction using efficient catalysts in eco-friendly media. Green Chem. 2019, 3, 381-405. [CrossRef]

8. Fliedel, C.; Ghisolfi, A.; Braunstein, P. Functional Short-Bite Ligands: Synthesis, Coordination Chemistry, and Applications of N-Functionalized Bis(diaryl/dialkylphosphino)amine-type Ligands. Chem. Rev. 2016, 116, 9237-9304. [CrossRef]

9. Phan, N.T.S.; Sluys, M.V.D.; Jones, C.W. On the Nature of the Active Species in Palladium Catalyzed Mizoroki-Heck and Suzuki-Miyaura Couplings-Homogeneous or Heterogeneous Catalysis, A Critical Review. Adv. Synth. Catal. 2006, 348, 609-679. [CrossRef]

10. Suzuki, A. Carbon-carbon bonding made easy. Chem. Commun. 2005, 4759-4763. [CrossRef]

11. Bellina, F.; Carpita, A.; Rossi, R. Palladium Catalysts for the Suzuki Cross-Coupling Reaction: An Overview of Recent Advances. Synthesis 2004, 2004, 2419-2440. [CrossRef]

12. Fliedel, C.; Labande, A.; Manoury, E.; Poli, R. Chiral N-heterocyclic carbene ligands with additional chelating group(s) applied to homogeneous metal-mediated asymmetric catalysis. Coord. Chem. Rev. 2019, 394, 65-103. [CrossRef]

13. Fortman, G.C.; Nolan, S.P. N-Heterocyclic carbene (NHC) ligands and palladium in homogeneous cross-coupling catalysis: A perfect union. Chem. Soc. Rev. 2011, 40, 5151-5169. [CrossRef] [PubMed]

14. Marion, N.; Nolan, S.P. Well-Defined N-Heterocyclic Carbenes-Palladium(II) Precatalysts for Cross-Coupling Reactions. Acc. Chem. Res. 2008, 41, 1440-1449. [CrossRef] [PubMed]

15. Maluenda, I.; Navarro, O. Recent Developments in the Suzuki-Miyaura Reaction: 2010-2014. Molecules 2015, 20, 7528-7557. [CrossRef]

16. Beletskaya, I.P.; Alonso, F.; Tyurin, V. The Suzuki-Miyaura Reaction after the Nobel Prize. Coord. Chem. Rev. 2019, 385, 137-173. [CrossRef]

17. Paul, S.; Islam, M.M.; Islam, S.M. Suzuki-Miyaura reaction by heterogeneously supported Pd in water: Recent studies. RSC Adv. 2015, 5, 42193-42221. [CrossRef]

18. Martin, R.; Buchwald, S.L. Palladium-Catalyzed Suzuki-Miyaura Cross-Coupling Reactions Employing Dialkylbiaryl Phosphine Ligands. Acc. Chem. Res. 2008, 41, 1461-1473. [CrossRef]

19. Barder, T.E.; Walker, S.D.; Martinelli, J.R.; Buchwald, S.L. Catalysts for Suzuki-Miyaura Coupling Processes: Scope and Studies of the Effect of Ligand Structure. J. Am. Chem. Soc. 2005, 127, 4685-4696. [CrossRef]

20. Littke, A.F.; Fu, G.C. Palladium-Catalyzed Coupling Reactions of Aryl Chlorides. Angew. Chem. Int. Ed. 2002, 41, 4176-4211. [CrossRef]

21. Garrett, C.E.; Prasad, K. The Art of Meeting Palladium Specifications in Active Pharmaceutical Ingredients Produced by Pd-Catalyzed Reactions. Adv. Synth. Catal. 2004, 346, 889-900. [CrossRef]

22. Poliakoff, M.; Fitzpatrick, J.M.; Farren, T.R.; Anastas, P.T. Green Chemistry: Science and Politics of Change. Science 2002, 297, 807-810. [CrossRef] [PubMed]

23. Yin, L.; Liebscher, J. Carbon-Carbon Coupling Reactions Catalyzed by Heterogeneous Palladium Catalysts. Chem. Rev. 2007, 107, 133-173. [CrossRef] [PubMed]

24. Taladriz-Blanco, P.; Hervés, P.; Pérez-Juste, J. Supported Pd Nanoparticles for Carbon-Carbon Coupling Reactions. Top. Catal. 2013, 56, 1154-1170. [CrossRef]

25. Islam, S.M.; Mondal, P.; Roy, A.S.; Mondal, S.; Hossain, D. Heterogeneous Suzuki and copper-free Sonogashira cross-coupling reactions catalyzed by a reusable palladium(II) complex in water medium. Tetrahedron Lett. 2010, 51, 2067-2070. [CrossRef]

26. Pol, V.G.; Grisaru, H.; Gedanken, A. Coating Noble Metal Nanocrystals (Ag, Au, Pd, and Pt) on Polystyrene Spheres via Ultrasound Irradiation. Langmuir 2005, 21, 3635-3640. [CrossRef] [PubMed]

27. Yamada, Y.M.A.; Takeda, K.; Takahashi, H.; Ikegami, S. An Assembled Complex of Palladium and Non-Cross-linked Amphiphilic Polymer: A Highly Active and Recyclable Catalyst for the Suzuki-Miyaura Reaction. Org. Lett. 2002, 4, 3371-3374. [CrossRef]

28. Ley, S.V.; Ramarao, C.; Gordon, R.S.; Holmes, A.B.; Morrison, A.J.; McConvey, I.F.; Shirley, I.M.; Smith, S.C.; Smith, M.D. Polyurea-encapsulated palladium(II) acetate: A robust and recyclable catalyst for use in conventional and supercritical media. Chem. Commun. 2002, 1134-1135. [CrossRef] 
29. Kunfi, A.; Mayc, Z.; Németh, P.; London, G. Polydopamine supported palladium nanoparticles: Highly efficient catalysts in Suzuki cross-coupling and tandem Suzuki cross-coupling/nitroarene reductions under green reaction conditions. J. Catal. 2018, 361, 84-93. [CrossRef]

30. Chen, X.; He, J.; Yan, C.; Tang, H. Novel In Situ Fabrication of Chestnut-Like Carbon Nanotube Spheres from Polypropylene and Nickel Formate. J. Phys. Chem. B 2006, 110, 21684-21689. [CrossRef]

31. Lu, A.-H.; Li, W.-C.; Hou, Z.; Schuth, F. Molecular level dispersed Pd clusters in the carbon walls of ordered mesoporous carbon as a highly selective alcohol oxidation catalyst. Chem. Commun. 2007, 1038-1040. [CrossRef]

32. Mitsudome, T.; Nose, K.; Mori, K.; Mizugaki, T.; Ebitani, K.; Jitsukawa, K.; Kaneda, K. Montmorillonite-entrapped sub-nanoordered Pd clusters as a heterogeneous catalyst for allylic substitution reactions. Angew. Chem. Int. Ed. 2007, 46, 3288-3290. [CrossRef] [PubMed]

33. Hoshiya, N.; Shimoda, M.; Yoshikawa, H.; Yamashita, Y.; Shuto, S.; Arisawa, M. Sulfur Modification of Au via Treatment with Piranha Solution Provides Low-Pd Releasing and Recyclable Pd Material, SAPd. J. Am. Chem. Soc. 2010, 132, 7270-7272. [CrossRef] [PubMed]

34. Jiang, Y.; Gao, Q. Heterogeneous Hydrogenation Catalyses over Recyclable Pd(0) Nanoparticle Catalysts Stabilized by PAMAM-SBA-15 Organic-Inorganic Hybrid Composites. J. Am. Chem. Soc. 2006, 128, 716-717. [CrossRef] [PubMed]

35. Dickshat, A.T.; Surmiak, S.; Studer, A. Pd Immobilized in Mesoporous Silica Particles as Recyclable Catalysts for Suzuki-Miyaura Coupling: Cooperative Effects Exerted by Co-Immobilized Amine Functionalities. Synlett 2013, 24, 1523-1528. [CrossRef]

36. Pandarus, V.; Desplantier-Giscard, D.; Gingras, G.; Ciriminna, R.; Cara, P.D.; Beland, F.; Pagliaro, M. Enhanced heterogeneously catalyzed Suzuki-Miyaura reaction over SiliaCat Pd(0). Tetrahedron Lett. 2013, 54, 4712-4716. [CrossRef]

37. Basudeb, B.; Susmita, P. An improved preparation of mesoporous silica-supported Pd as sustainable catalysts for phosphine-free Suzuki-Miyaura and Heck coupling reactions. Appl. Organomet. Chem. 2013, 27, 588-594.

38. Webb, J.D.; MacQuarrie, S.; McEleney, K.; Crudden, C.M. Mesoporous silica-supported Pd catalysts: An investigation into structure, activity, leaching and heterogeneity. J. Catal. 2007, 252, 97-109. [CrossRef]

39. Paul, S.; Clark, J.H. Structure-Activity Relationship between Some Novel Silica Supported Palladium Catalysts: A Study of the Suzuki Reaction. J. Mol. Catal. A Chem. 2004, 215, 107-111. [CrossRef]

40. Baleizao, C.; Corma, A.; Garcia, H.; Leyva, A. An oxime-carbapalladacycle complex covalently anchored to silica as an active and reusable heterogeneous catalyst for Suzuki cross-coupling in water. Chem. Commun. 2003, 606-607. [CrossRef]

41. Kirschning, A. (Ed.) Immobilized Catalysts. Solid Phases, Immobilization and Applications; Series: Topics in Current Chemistry; Springer: Berlin, Germany, 2004; Volume 242.

42. Wang, F.; Mielby, J.; Herrmann Richter, F.; Wang, G.; Prieto, G.; Kasama, T.; Weidenthaler, C.; Bongard, H.-J.; Kegnæs, S.; Alois Fürstner, F.; et al. Polyphenylene Support for Pd Catalysts with Exceptional Catalytic Activity. Angew. Chem. Int. Ed. 2014, 53, 8645-8648. [CrossRef]

43. Biffis, A.; Centomo, P.; Del Zotto, A.; Zecca, M. Pd Metal Catalysts for Cross-Couplings and Related Reactions in the 21st Century: A Critical Review. Chem. Rev. 2018, 118, 2249-2295. [CrossRef] [PubMed]

44. Broadwater, S.J.; Tyler McQuade, D. Investigating PdEnCat Catalysis. J. Org. Chem. 2006, 71, $2131-2134$. [CrossRef] [PubMed]

45. Park, C.M.; Kwon, M.S.; Park, J. Palladium Nanoparticles in Polymers: Catalyst for Alkene Hydrogenation, Carbon-Carbon Cross-Coupling Reactions, and Aerobic Alcohol Oxidation. Synthesis 2006, 22, 3790-3794. [CrossRef]

46. Evangelisti, C.; Panziera, N.; Pertici, P.; Vitulli, G.; Salvadori, P.; Battocchio, C.; Polzonetti, G. Palladium nanoparticles supported on polyvinylpyridine: Catalytic activity in Heck-type reactions and XPS structural studies. J. Catal. 2009, 262, 287-293. [CrossRef]

47. Jumde, R.P.; Marelli, M.; Scotti, N.; Mandoli, A.; Psaro, R.; Evangelisti, C. Ultrafine palladium nanoparticles immobilized into poly(4-vinylpyridine)-based porous monolith for continuous-flow Mizoroki-Heck reaction. J. Mol. Catal. A Chem. 2016, 414, 55-61. [CrossRef]

48. Oberhauser, W.; Evangelisti, C.; Jumde, R.P.; Petrucci, G.; Bartoli, M.; Frediani, M.; Mannini, M.; Capozzoli, L.; Passaglia, E.; Rosi, L. Palladium-nanoparticles on end-functionalized poly(lactic acid)-based stereocomplexes for the chemoselective cinnamaldehyde hydrogenation: Effect of the end-group. J. Catal. 2015, 330, 187-196. [CrossRef] 
49. Köhler, K.; Heidenreich, R.G.; Soomro, S.S.; Pröckl, S.S. Supported Palladium Catalysts for Suzuki Reactions: Structure-Property Relationships, Optimized Reaction Protocol and Control of Palladium Leaching. Adv. Synth. Catal. 2008, 350, 2930-2936. [CrossRef]

50. Joucla, L.; Cusati, G.; Pinel, C.; Djakovitch, J. One-Pot Suzuki/Heck Sequence for the Synthesis of (E)-Stilbenes Featuring a Recyclable Silica-Supported Palladium Catalyst via a Multi-Component Reaction in 1,3-Propanediol. Adv. Synth. Catal. 2010, 352, 1993-2001. [CrossRef]

51. Soomro, S.S.; Ansari, F.L.; Chatziapostolou, K.; Köhler, K. Palladium Leaching Dependent on Reaction Parameters in Suzuki-Miyaura Coupling Reactions Catalyzed by Palladium Supported on Alumina under Mild Reaction Conditions. J. Catal. 2010, 273, 138-146. [CrossRef]

52. Collins, G.; Schmidt, M.; O’Dwyer, C.; Holmes, J.D.; McGlacken, G.P. The Origin of Shape Sensitivity in Palladium-Catalyzed Suzuki-Miyaura Cross Coupling Reactions. Angew. Chem. Int. Ed. 2014, 53, 4142-4145. [CrossRef]

53. Ji, J.; Li, Y.; Fu, W.; Cui, Z.; Shen, J.; Ye, M. Self-assembled three-dimensional Pd/MoS2/reduced graphene oxide nanocatalyst: A case for homogeneous leaching mechanism. J. Coll. Interface Sci. 2017, 505, 983-994. [CrossRef] [PubMed]

54. Klingelhöfer, S.; Heitz, W.; Greiner, A.; Oestreich, S.; Förster, S.; Antonietti, M. Preparation of Palladium Colloids in Block Copolymer Micelles and Their Use for the Catalysis of the Heck Reaction. J. Am. Chem. Soc. 1997, 119, 10116-10120. [CrossRef]

55. Caporusso, A.M.; Innocenti, P.; Aronica, L.A.; Vitulli, G.; Gallina, R.; Biffis, A.; Zecca, M.; Corain, B. Functional resins in palladium catalysis: Promising materials for Heck reaction in aprotic polar solvents. J. Catal. 2005, 234, 1-13. [CrossRef]

(C) 2020 by the authors. Licensee MDPI, Basel, Switzerland. This article is an open access article distributed under the terms and conditions of the Creative Commons Attribution (CC BY) license (http://creativecommons.org/licenses/by/4.0/). 